\title{
Association between Non-Cigarette/Smokeless Tobacco and Hypertension in the National Health Interview Survey: A Pseudo-Panel Analysis
}

\author{
Olawunmi Obisesan $^{1,2}$, Emmanuel Thompson ${ }^{2}$, Adekunle Obisesan ${ }^{3}$, Olubusayo Akinola ${ }^{4}$, \\ Yvonne Commodore-Mensah ${ }^{5}$ \\ ${ }^{1}$ Emory University, Rollins School of Public Health, Atlanta, GA, USA \\ ${ }^{2}$ Southeast Missouri State University, Cape Girardeau, MO, USA \\ ${ }^{3}$ Southeast Hospital, Cape Girardeau, MO, USA \\ ${ }^{4}$ Economic Community of West African States (ECOWAS), Abuja, Nigeria \\ ${ }^{5}$ Emory University, Nell Hodgson Woodruff School of Nursing, Atlanta, GA, USA
}

\begin{tabular}{l}
\hline \hline Article Info \\
\hline Article history: \\
Received Feb 02, 2016 \\
Revised Feb 22, 2016 \\
Accepted Feb 28, 2016 \\
\hline
\end{tabular}

\section{Keyword:}

Hypertension

Non-cigarette tobacco

Smokeless tobacco

Cardiovascular risks

Pseudo-panel analysis

\begin{abstract}
This study sought to examine assumption between having ever used noncigarette tobacco or smokeless tobacco, and a diagnosis of hypertension among a sample of 13,086 United States adults participating in the National Health Interview Series from 2012-2014. A pseudo-panel analysis of data extracted from the Integrated Health Interview Series Survey was conducted. The generalized linear mixed model was used to quantify the effect of a history of non-cigarette tobacco, smokeless tobacco, and socio-demographic predictor variables on the response variable, a diagnosis of hypertension. The transformed data, based on the pseudo-panel technique, resulted in fiftyseven (57) birth cohorts and followed in 2012, 2013, and 2014. The mean age was 51.6 years $( \pm 12.4)$. The findings of this study revealed that the odds of hypertension diagnosis for non-cigarette tobacco users was 0.8846 times lower (95\% CI: $0.7907,0.9896)$ than non-users after adjusting for possible confounders such as age, language, education, income and years of smoking. Our study suggested that the association between the use of non-cigarette tobacco and the diagnosis of hypertension among the sample population is consistent enough to assume a less plausible association between the two variables.
\end{abstract}

Copyright () 2016 Institute of Advanced Engineering and Science. All rights reserved.

\section{Corresponding Author:}

Olawunmi Obisesan,

Emory University,

Rollins School of Public Health,

1518 Clifton Rd, Atlanta, GA, USA.

Email: oobisesan@gmail.com

\section{INTRODUCTION}

Tobacco use is a major risk for hypertension and cardiovascular disease (CVD) and is the most important cause of premature death in the United States [1]. Non-cigarette tobacco and smokeless tobacco have been shown to increase the risk of CVD in comparison to non-smokers [1]. Hypertension on its own is a major risk factor for CVD morbidity and mortality [2]. Tobacco-related illnesses and hypertension in the US costs more than $\$ 300$ billion [3] and \$46 billion [4] a year respectively. Many studies have examined an association between hypertension and tobacco smoking (cigarette and non-cigarette) but the exact relationship has remained unclear [1],[5],[6]. Experts have projected that tobacco use will kill an estimated 1 billion people in the 21 st century [7]. Tobacco use in other forms, besides cigarette, will also contribute to increased morbidity and mortality rates globally [7]. 
The continued use of non-cigarette tobacco is promoted by some tobacco companies under the claim of a negligible or smaller health risk, hence non-cigarette tobacco (NCT) which fall under the three broad categories of other smoked products, smokeless tobacco and nicotine products are less regulated than cigarettes [6],[8]. In order to minimize passive exposure to smoke and to reduce harm attributed to inveterate smokers, smokeless tobacco (ST) was introduced as a substitute for cigarette smoking, and a major adjunct for smoking cessation [9]. Experts have, however, disagreed, warning that some non-cigarette tobacco products are still harmful since these contain certain ingredients, including glycyrrhizinic acid that leads to potassium wasting and sodium retention which act as buffers for the facilitation of nicotine absorption. These have been found to cause an aggravation of hypertension and increase the risk for chronic diseases including CVD [1],[7]-[10],[11]. While some researchers have found no difference in the prevalence of hypertension among users of non-cigarette tobacco products [12]-[14], others have found an association between the use of non-cigarette tobacco and hypertension [10],[15]-[17].

In the United States, the statistics for those who use NCT is unavailable. However, an estimated 8.1 million people (3.2\% of the total population) use ST, most users being males, age $18-25$ years [1]. The use of ST is commonest among Native Americans (7\%) and Whites (4.3\%) as well as among lower socio-economic groups, including blue-collar/unskilled/unemployed workers and non-college graduates whose health statuses may already be influenced by other social determinants of health [1]. In the 12-17 year age group, data from 2002-2007 shows a more than 10-fold higher prevalence of use among boys $(6.3 \%)$ than girls $(0.4 \%)$ [1]. Despite some claims that smokeless tobacco is less harmful than cigarette smoking, the fact still remains that users are exposed to harmful chemicals that could heighten their risk for several health problems just as with cigarette smoking [9].

Many epidemiological studies have examined the association between cigarettes and hypertension but in recent years, only minimal research has been done on the health effects of non-cigarette tobacco [18],[19]. Given the morbidity, mortality and cost associated with smoking, it is expedient to establish the role of ST products in the development of CVD risk factors such as hypertension [6]. The purpose of this study was to examine the association between ever smoked non-cigarette tobacco in one's lifetime and a diagnosis of hypertension in a nationally-representative sample of US adults.

\section{RESEARCH METHOD}

\subsection{Study design and population}

Data was extracted from the Integrated Health Interview Series (IHIS) dataset which comprise of repeated cross-sectional samples for 2012, 2013, and 2014. The IHIS is derived from the National Health Interview Survey (NHIS) public use datasets. The NHIS is the principal source of information on the health of the US population and is a cross-sectional household interview survey. The sampling plan follows a multistage area probability design that permits the representative sampling of households and noninstitutionalized individuals with oversampling of Blacks and Hispanics.

\subsection{Variables definition and measures}

The data for this study was extracted from the Integrated Health Interview Series (IHIS) dataset which comprise of repeated cross-sections for 2012, 2013, and 2014. The IHIS is based on original data from National Health Interview Survey (NHIS) public dataset. The variables used from the IHIS dataset included: ever told had hypertension on 2+ visits (HYP2TIME), age (AGE), language of interview (INTERVLANG), education attainment (EDUCREC2), person's total earnings (EARNINGS), ever smoked non-cigarette tobacco products (NONCIGEV), and ever used smokeless tobacco (SMKLSEV). Apart from HYP2TIME that was used as the response variable, the rest were predictor variables. Hypertension was defined as two or more occasions of elevated blood pressure at office visits per national guidelines [20] Educational attainment was defined as: $1=$ never attended/kindergarten, $2=$ grade $1,3=$ grade $2,4=$ grade $3,5=$ grade $4,6=$ grade $5,7=$ grade $6,8=$ grade $7,9=$ grade $8,10=$ grade $9,11=$ grade $10,12=$ grade $11,13=12$ th grade, no diploma, $14=$ high school graduate, $15=$ GED or equivalent, $16=$ some college, no degree, $17=\mathrm{AA}$ degree: Technical/vocational/occupational, 18 = AA degree: Academic program, 19 = Bachelor's degree (BA, AB, BS, BBA), 20 = Master's degree (MA, MS, Meng, Med, MBA), 21 = Professional degree (MD, DDS, DVM, JD), and 22 = Doctoral degree. Language of interview was categorized as English, Spanish, English and Spanish or Other. Earnings were classified as: $1=\$ 01$ to $\$ 4999,2=\$ 5000$ to $\$ 9999,3=\$ 10000$ to $\$ 14999$, $4=\$ 15000$ to $\$ 19999,5=\$ 20000$ to $\$ 24999,6=\$ 25000$ to $\$ 34999,7=\$ 35000$ to $\$ 44999,8=\$ 45000$ to $\$ 54999,9=\$ 55000$ to $\$ 64999,10=\$ 65000$ to $\$ 74999$, and $11=\$ 75000$ and over. 


\subsection{Statistical analyses}

Frequencies and percentages were descriptive measures used to summarize the categorical variables, while mean and standard deviation were used to describe the continuous variable (AGE). In the modeling process, age was transformed to a value on a logarithm scale. The generalized linear mixed model (GLMM) with a logit link was used to quantify the effect of each of the predictors on the response variable. A detailed description of the model is shown under 2.4. Quite importantly, the use of the IHIS dataset has one main drawback because same subjects were not followed through time, hence historical information on subjects were not available. This drawback imposes limitation to the use of panel data models. To overcome this limitation, Deaton (1985) [21] suggests following cohorts due to the accessibility of household surveys. We therefore constructed a pseudo-panel by pulling individual subjects sharing common year of birth from one survey year to another in accordance with [21]. Each year of birth forms a birth cohort. The birth cohort for each individual subject can be obtained by subtracting the age of the subject from the year he/she participated in the survey.

\subsection{Generalized Linear Mixed Model}

This part of the study outlines the main features of the GLMM. The GLMM contains both fixed effects and random effects. It is an extension of the generalized linear model (GLM) by adding random effects to the linear predictor component. A GLM is a regression model defined within the distributional structure of the exponential family and is given as follows:

$$
\mathrm{f}_{\mathrm{Y}}(\mathrm{y})=\exp \left(\frac{\mathrm{y} \theta-\psi(\theta)}{\phi}+\mathrm{c}(\mathrm{y}, \phi)\right)
$$

where $\mu=\mathrm{E}[\mathrm{y}]=\psi^{\prime}(\theta), \operatorname{Var}[\mathrm{y}]=\phi \psi^{\prime \prime}(\theta)=\phi \mathrm{V}(\mu)$. V( $\left.\mu\right)$ captures the relationship between $\mathrm{E}[\mathrm{y}]$ and $\operatorname{Var}[\mathrm{y}]$. The GLM can therefore be represented as:

$$
g(\mu)=\eta=X \beta
$$

where $\beta, \mathrm{p}$-dimensional vector; $\mathrm{X},(\mathrm{m} \times \mathrm{p})$ vector of predictors; $\mathrm{g}$, a link function; $\eta$, a linear predictor. $\beta$ estimates are obtained by using an iterative numerical approach to solve maximum likelihood equations. GLMMs extend GLMs by including random effects $\mathrm{Zu}$ to the linear predictor shown in (2). The random effects allow cohort-specific prediction, heterogeneity between cohorts, and structural correlation within cohorts. Conditional on a q-dimensional vector $\mathrm{u}_{\mathrm{i}}$ of random effects for cohort $\mathrm{i}$, GLMM assumes for the $\mathrm{j}^{\text {th }}$ response on cohort $\mathrm{i}, \mathrm{y}_{\mathrm{ij}}$ are:

$$
\begin{array}{r}
y_{i j} \mid u_{i} \sim f_{Y_{i j} \mid u_{i}}\left(y_{i j} \mid u_{i}\right), u_{i} \sim f_{U}\left(u_{i}\right), \\
f_{Y_{i j} \mid u_{i}}\left(y_{i j} \mid u_{i}\right)=\exp \left(\frac{y_{i j} \theta_{i j}-\psi\left(\theta_{i j}\right)}{\phi}+c\left(y_{i j}, \phi\right)\right)
\end{array}
$$

The following relations hold:

1. $\mu_{\mathrm{ij}}=\mathrm{E}\left[\mathrm{y}_{\mathrm{ij}} \mid \mathrm{u}_{\mathrm{i}}\right]=\psi^{\prime}\left(\theta_{\mathrm{ij}}\right)$

2. $\operatorname{Var}\left[y_{i j} \mid u_{i}\right]=\phi \psi^{\prime \prime}\left(\theta_{i j}\right)=\phi V\left(\mu_{i j}\right)$

A function of $\mu_{\mathrm{ij}}$ which is linear in both $\beta$ and $\mathrm{u}_{\mathrm{i}}$ is given by:

$$
g\left(\mu_{\mathrm{ij}}\right)=X_{\mathrm{ij}}^{\prime} \beta+\mathrm{Z}_{\mathrm{ij}}^{\prime} \mathrm{u}_{\mathrm{i}}
$$

Where $\mathrm{X}_{\mathrm{ij}}$ and $\mathrm{Z}_{\mathrm{ij}}$ are $\mathrm{p}$ and $\mathrm{q}$ dimensional vectors of known predictors for fixed and random effects respectively. The random effects signify the impact of cohort $i$ on its repeated observation that is not captured by the observed predictor. With these random effects, the idea is that, the sampled cohorts are thought to represent a population of all possible cohorts and most often assumed to follow a normal distribution with zero mean and variance $\sigma_{\mathrm{u}}^{2}$. 


\subsection{Estimation}

The likelihood associated with (3) is given by:

$$
L(\beta, D \mid y)=\int f_{Y \mid u} f_{U}(u) d u
$$

Maximum likelihood estimation and estimation of $\beta$ and D are hampered by the integral in (5), therefore approximate techniques are used for the estimation. Techniques such as the Laplace, pseudo likelihood, and numerical integration have been proposed in the literature [22]. In our case, we used numerical integration based on the adaptive Gauss-Hermite quadrature [23]. To estimate the relationship between HYP2TIME and the six (6) predictors, the present study assumes a normal distribution for the random effects and a logit link for $\mathrm{g}$. The logit link was appropriate because our response variable "HYP2TIME" can take one of two possible values representing "yes" or "no" to ever told had hypertension on $2+$ visits. To determine statistical significance, we used odds ratio estimated from the GLMM with the logit link and the associated $(1-\alpha) \%$ confidence interval where $\alpha$ represents the level of significance. RStudio version 0.99.446 (RStudio, Inc.) statistical package was used for the analysis.

\section{RESULTS AND ANALYSIS}

\subsection{Descriptive Statistics}

Of 13,086 participants involved in the study, 4,284 (32.74\%), 4,140 (31.64\%), and 4,662 (35.63\%) were from 2012, 2013, and 2014 survey years respectively. The transformed data based on the pseudo-panel technique resulted in fifty-seven (57) birth cohorts and each cohort was followed in 2012, 2013, and 2014. The youngest and the oldest participants were 21 and 79 years old respectively. Also, the average age of participants was 51.6 years with a standard deviation of 12.4 years.

Figure 1 shows the proportion of participants for each of the 57 birth cohorts who had hypertension during the 2012, 2013, and 2014 surveys. Each line represents a birth cohort and the proportions for all the birth cohorts range from 0.40 (2012 survey) to 1.00 (2014 survey). The minimum and the maximum proportions during the 2012 survey were associated with the $1991(0.40)$ and the 1935 (1.00) birth cohorts respectively. While the minimum and maximum proportions during the 2013 survey were respectively connected to the 1988 (0.41) and 1945 (0.98) birth cohorts. In the 2014 survey, the minimum and the maximum proportions were 0.52 and 1.00 respectively linked to the 1989 and the 1939 birth cohorts. Broadly speaking, the proportions among all the 57 birth cohorts were consistently above 0.4 apart from that of 1991 during the 2012 survey.

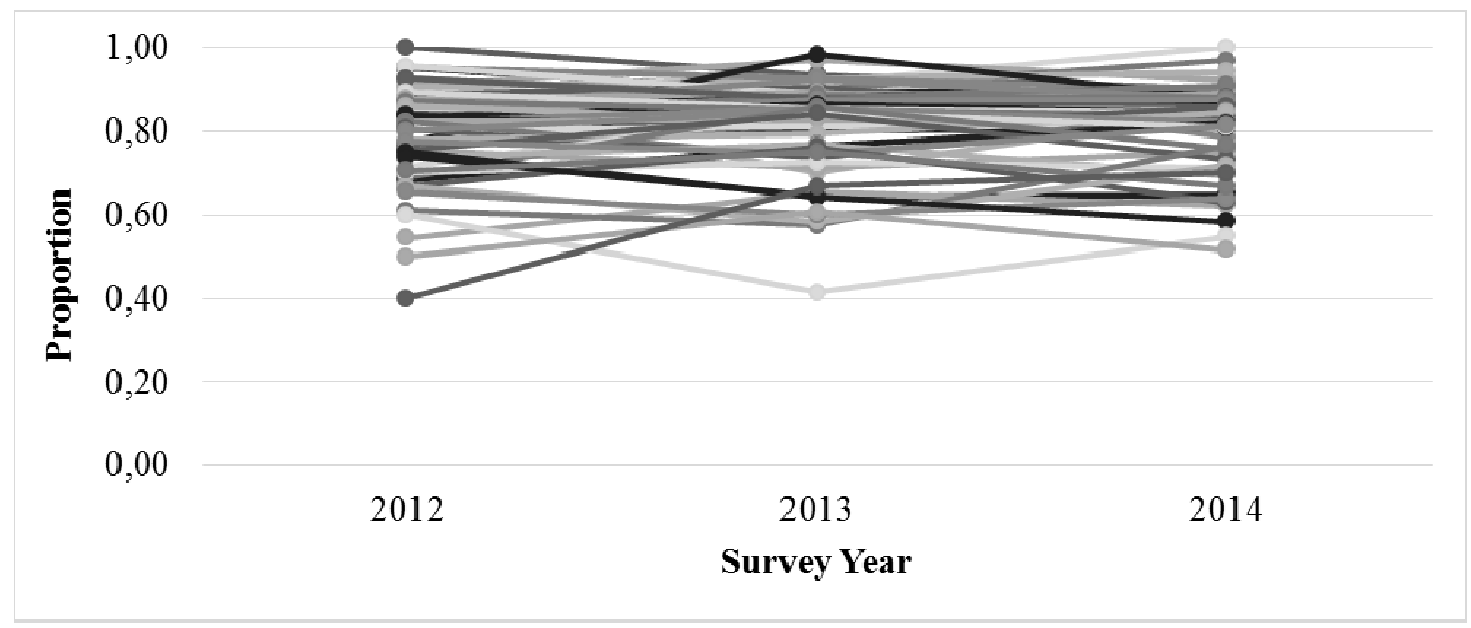

Figure 1. Proportion with hypertension in each birth cohort

Figure 2 displays the proportion of participants who had hypertension by educational attainment. Large variations in proportions were observed at grade 2 during the 2013 and 2014 survey years. It can further be observed that, the variabilities tend to dwindle and proportions move closer to each other as we move from lower level of EDUCREC2 to higher levels with some minor depature starting from the third

Association between Non Cigarette/Smokeless Tobacco and Hypertension in the .... (Olawunmi Obisesan) 
highest level in 2012. Almost all the proportions during the three survey years consistently were above 0.60 in exception of one which was observed at grade 2 (0.33) during 2013 survey.

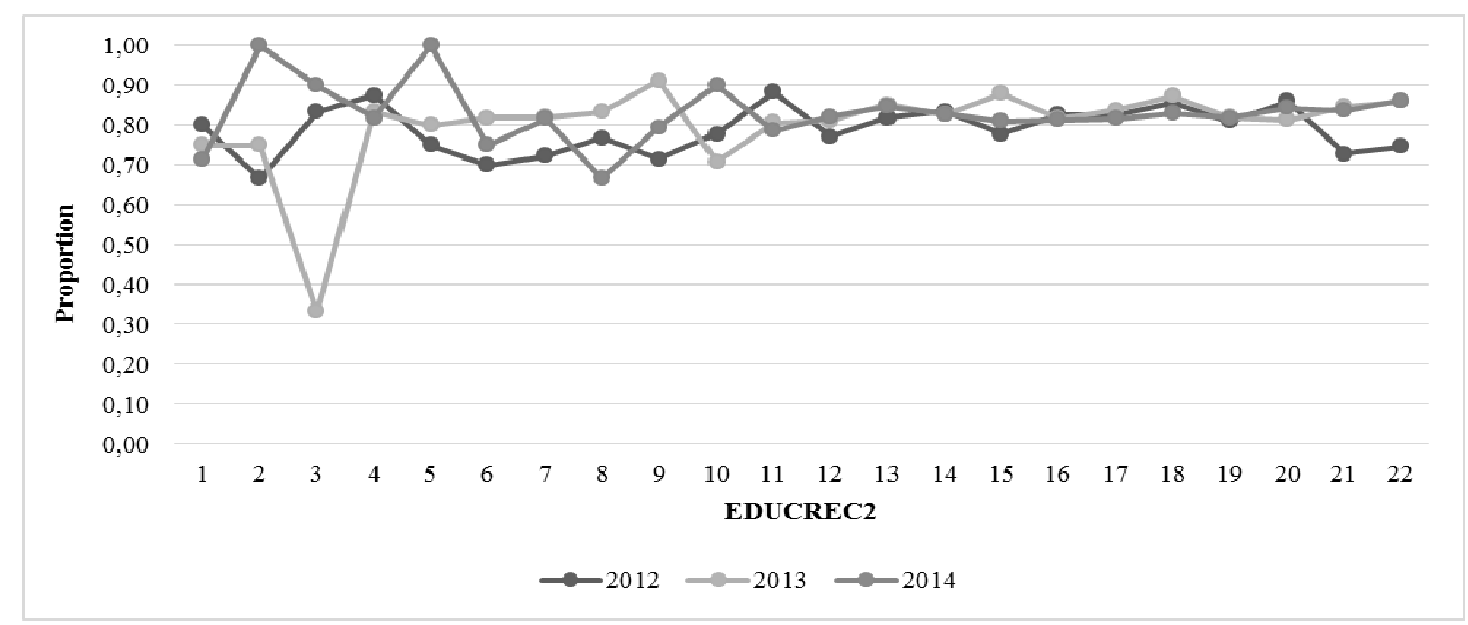

Figure 2. Proportion with hypertension by educational attainment

Figure 3 shows the proportion of participants who had hypertension by language of interview within the 3-year span of the survey in the Spanish ethnic populations. There was also an observed increase in hypertension diagnosis among individuals who speak other languages apart from English and Spanish in 2014 (Figure 3). It could further be observed that clear understanding of diagnosis and possible diagnostic implications based on language had positive effect on the proportion of observed hypertension diagnosis amongst the English speaking populations with no observed changes within the 3 years of survey.

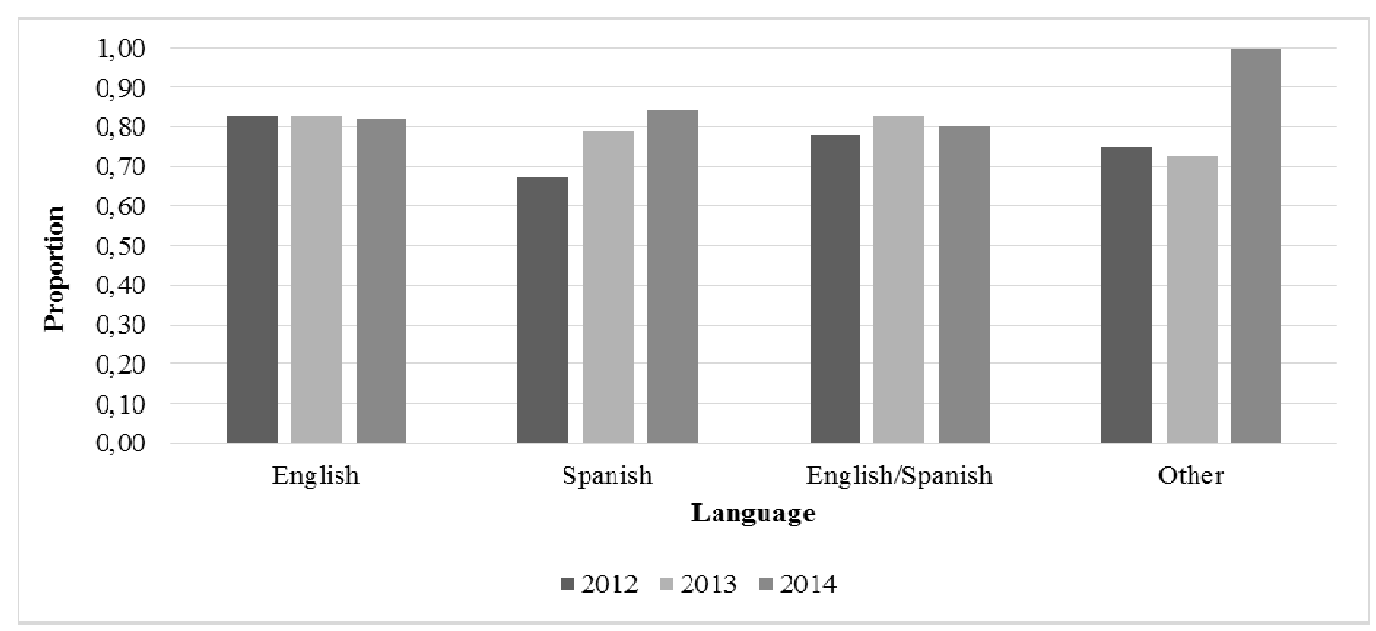

Figure 3. Proportion responded yes to HYP2TIME by INTERVLANG

Figure 4 displays the proportion of participants with hypertension diagnosis by earnings. The lowest proportions were observed among earning groups 4, 3, and 6 in 2012, 2013, and 2014 respectively. Further, the highest proportions were recorded among earning groups 2, 5, and 1 in 2012, 2013, and 2014 respectively. 


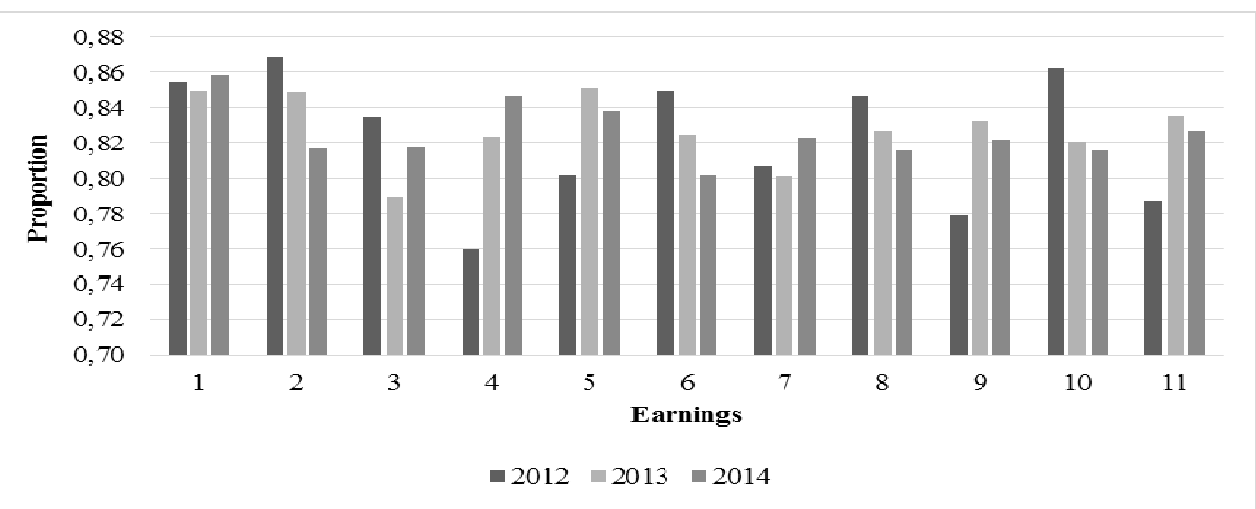

Figure 4. Proportion responded yes to HYP2TIME by EARNINGS

Figures 5 and Figure 6 display the proportion of participants that had a hypertension diagnosis by ever smoked non-cigarette tobacco products and ever used smokeless tobacco respectively. The proportion with hypertension diagnosis increased marginally from 0.83 in 2012 to 0.84 in 2014 among those who had never used NCT. However the proportion declined from about 0.81 to 0.79 between 2012 and 2014 for those who had ever used NCT. Also, the proportion with hypertension diagnosis rose by $1 \%(0.82$ to 0.83$)$ between 2012 and 2014 among those had never used ST. While, the proportion had ever used ST but had a hypertension diagnosis dropped by 3\% (0.81-0.78) from 2012 to 2014.

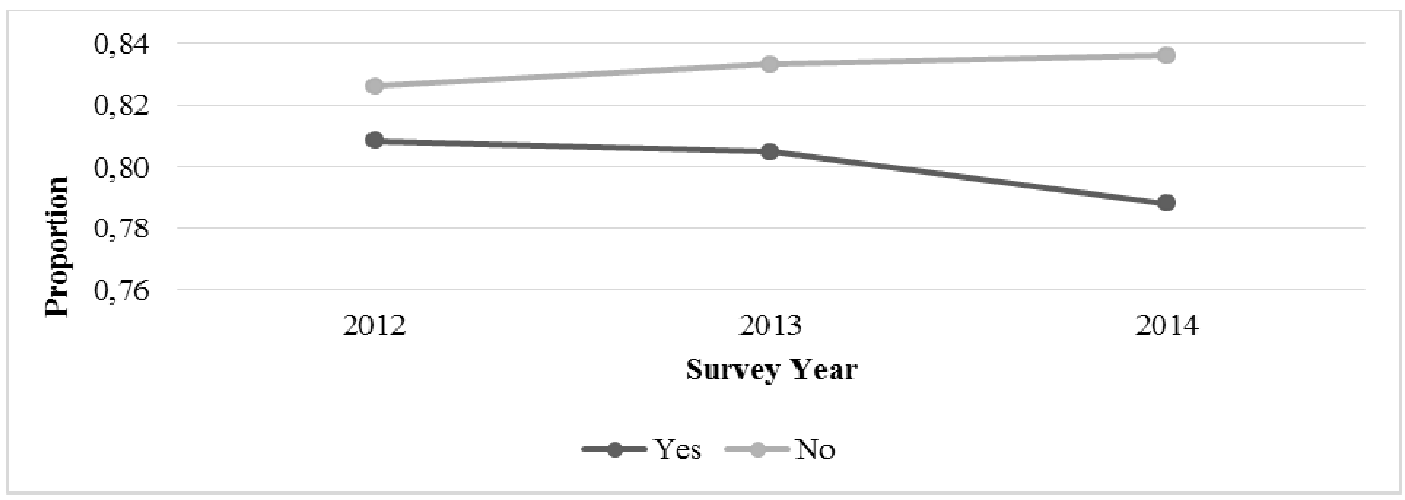

Figure 5. Proportion responded yes to HYP2TIME by NONCIGEV

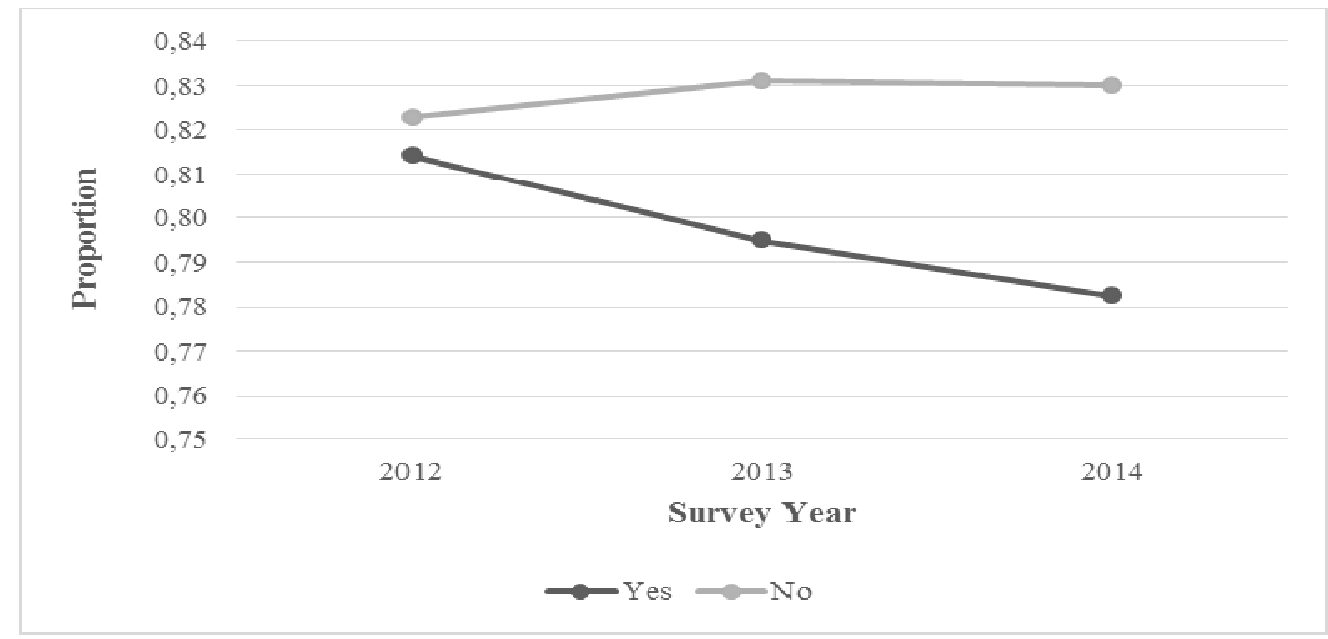

Figure 6. Proportion responded yes to HYP2TIME by SMKLSEV 


\subsection{Odds Ratio Analysis}

Table 1 shows the estimated odds ratios and their corresponding 95\% confidence intervals from the GLMM model with the logit link. Here, we focus on significant effects. Our analysis revealed that the odds of hypertension diagnosis for those who responded 'yes' to the use of NCT was 0.8846 times lower (95\% CI $.7907, .9896)$ than those who responded 'no', after adjusting for the confounders of age, language, education, income and years of smoking.

Table 1. Estimated GLMM with a Logit Link

\begin{tabular}{|c|c|c|c|c|c|c|}
\hline Parameter & Estimate & SE & $\mathrm{Z}$ ratio & P value & Odds ratio & $95 \% 9 C I$ \\
\hline Intercept & -5.2516 & 0.5409 & -9.7090 & 0.0000 & 0.0052 & $(0.0018,0.0151)$ \\
\hline $\log (\mathrm{AGE})$ & 1.6849 & 0.0834 & 20.2090 & 0.0000 & 5.3917 & $(4.5789,6.3489)$ \\
\hline INTERVLANG 2 & -0.3056 & 0.1459 & -2.0940 & 0.0363 & 0.7367 & $(0.5534,0.9807)$ \\
\hline INTERVLANG 3 & -0.0284 & 0.2033 & -0.1400 & 0.8888 & 0.9720 & $(0.6525,1.4478)$ \\
\hline INTERVLANG 4 & 0.1609 & 0.4895 & 0.3290 & 0.7424 & 1.1745 & $(0.4500,3.0655)$ \\
\hline EARNINGS 2 & -0.0273 & 0.1389 & -0.1970 & 0.8440 & 0.9730 & $(0.7411,1.2775)$ \\
\hline EARNINGS 3 & -0.2353 & 0.1275 & -1.8460 & 0.0649 & 0.7903 & $(0.6155,1.0147)$ \\
\hline EARNINGS 4 & -0.2308 & 0.1306 & -1.7680 & 0.0771 & 0.7939 & $(0.6146,1.0254)$ \\
\hline EARNINGS 5 & -0.1011 & 0.1298 & -0.7790 & 0.4359 & 0.9038 & $(0.7008,1.1656)$ \\
\hline EARNINGS 6 & -0.1775 & 0.1165 & -1.5230 & 0.1277 & 0.8374 & $(0.6664,1.0522)$ \\
\hline EARNINGS 7 & -0.3167 & 0.1191 & -2.6600 & 0.0078 & 0.7286 & $(0.5769,0.9201)$ \\
\hline EARNINGS 8 & -0.2218 & 0.1255 & -1.7670 & 0.0772 & 0.8011 & $(0.6264,1.0245)$ \\
\hline EARNINGS 9 & -0.3605 & 0.1324 & -2.7230 & 0.0065 & 0.6973 & $(0.5379,0.9039)$ \\
\hline EARNINGS 10 & -0.2360 & 0.1486 & -1.5880 & 0.1122 & 0.7898 & $(0.5903,1.0568)$ \\
\hline EARNINGS 11 & -0.3572 & 0.1201 & -2.9760 & 0.0029 & 0.6996 & $(0.5529,0.8852)$ \\
\hline EDUCREC2 2 & 0.2848 & 0.8946 & 0.3180 & 0.7503 & 1.3295 & $(0.2302,7.6769)$ \\
\hline EDUCREC2 3 & 0.2490 & 0.7071 & 0.3520 & 0.7247 & 1.2827 & $(0.3208,5.1286)$ \\
\hline EDUCREC2 4 & 0.5391 & 0.6469 & 0.8330 & 0.4047 & 1.7144 & $(0.4825,6.0922)$ \\
\hline EDUCREC2 5 & 0.4322 & 0.6945 & 0.6220 & 0.5338 & 1.5406 & $(0.3949,6.0099)$ \\
\hline EDUCREC2 6 & -0.0615 & 0.5705 & -0.1080 & 0.9142 & 0.9403 & $(0.3074,2.8769)$ \\
\hline EDUCREC2 7 & 0.2629 & 0.4590 & 0.5730 & 0.5668 & 1.3007 & $(0.5290,3.1984)$ \\
\hline EDUCREC2 8 & -0.0124 & 0.5706 & -0.0220 & 0.9827 & 0.9877 & $(0.3228,3.0220)$ \\
\hline EDUCREC2 9 & 0.3415 & 0.4869 & 0.7010 & 0.4831 & 1.4070 & $(0.5418,3.6536)$ \\
\hline EDUCREC2 10 & 0.4315 & 0.4606 & 0.9370 & 0.3489 & 1.5396 & $(0.6242,3.7975)$ \\
\hline EDUCREC2 11 & 0.3981 & 0.4542 & 0.8760 & 0.3808 & 1.4890 & $(0.6113,3.6269)$ \\
\hline EDUCREC2 12 & 0.3281 & 0.4459 & 0.7360 & 0.4619 & 1.3883 & $(0.5793,3.6269)$ \\
\hline EDUCREC2 13 & 0.6130 & 0.4542 & 1.3500 & 0.1771 & 1.8460 & $(0.7579,4.4963)$ \\
\hline EDUCREC2 14 & 0.5352 & 0.4216 & 1.2700 & 0.2043 & 1.7077 & $(0.7475,3.9016)$ \\
\hline EDUCREC2 15 & 0.5587 & 0.4381 & 1.2750 & 0.2022 & 1.7484 & $(0.7409,4.1260)$ \\
\hline EDUCREC2 16 & 0.5286 & 0.4223 & 1.2520 & 0.2107 & 1.6965 & $(0.7415,3.8815)$ \\
\hline EDUCREC2 17 & 0.5355 & 0.4265 & 1.2550 & 0.2093 & 1.7083 & $(0.7404,3.9412)$ \\
\hline EDUCREC2 18 & 0.7646 & 0.4351 & 1.7570 & 0.0789 & 2.1481 & $(0.9156,5.0399)$ \\
\hline EDUCREC2 19 & 0.5300 & 0.4232 & 1.2520 & 0.2104 & 1.6990 & $(0.7412,3.8941)$ \\
\hline EDUCREC2 20 & 0.5985 & 0.4289 & 1.3950 & 0.1629 & 1.8194 & $(0.7850,4.2173)$ \\
\hline EDUCREC2 21 & 0.4005 & 0.4684 & 0.8550 & 0.3926 & 1.4926 & $(0.5959,3.7382)$ \\
\hline EDUCREC2 22 & 0.4012 & 0.4607 & 0.8710 & 0.3838 & 1.4937 & $(0.6055,3.6846)$ \\
\hline NONCIGEV (YES) & -0.1227 & 0.0573 & -2.1420 & 0.0322 & 0.8846 & $(0.7907,0.9896)$ \\
\hline SMKLSEV (YES) & 0.0435 & 0.0717 & 0.6070 & 0.5437 & 1.0445 & $(0.9076,1.2021)$ \\
\hline YEAR 2 & 0.0315 & 0.0585 & 0.5390 & 0.5899 & 1.0320 & $(0.9203,1.1574)$ \\
\hline YEAR 3 & -0.0131 & 0.0566 & -0.2320 & 0.8166 & 0.9870 & $(0.8833,1.1028)$ \\
\hline
\end{tabular}

\section{DISCUSSION}

This study adopted a pseudo-panel data analysis approach to estimate the effect of NCT and ST use and other socio-demographic variables on the diagnosis of hypertension in cohorts defined by year of birth in a three-year period, 2012-2014. The finding of this study show lower odds of hypertension diagnosis with age among who responded 'yes' to the use of NCT compared to those who responded 'no'. Friedman et al. (1982) [24] reported non-smokers had a higher mean diastolic blood pressure (1 mmHg higher) than smokers, regardless of gender. A notable limitation of this study is that the characteristics of the reference group (those who do not use ST and NCT, body mass index [BMI] status) are not known and may have included people who use cigarettes or who were obese. A comparison between non-smokers, smokers and former smokers in the Czech Republic by Pankova et al (2015) [13] showed no difference in the diagnosis of hypertension 
despite an adjustment for age and BMI. The authors, however, found the diagnosis of hypertension was more likely in non-smokers compared to former smoker. Another limitation is we did not adjust for all possible confounders that could affect the relationship between NCT, ST, and the diagnosis of hypertension, including body mass index (BMI). Future studies should investigate patients' knowledge of the deleterious effects of non-cigarette tobacco on cardiovascular disease risk.

\section{CONCLUSION}

Given the sodium content of non-cigarette tobacco products, regardless of lower odds of developing hypertension, a large number of aged individuals who use these products should still be considered at risk, in some form, for developing hypertension or poor control of their blood pressure. In screening for tobacco use, healthcare providers should screen for the use of both cigarette and non-cigarette tobacco products in their patients as well as initiate individualized health education messages that target tobacco cessation in all forms.

\section{REFERENCES}

[1] Piano MR., Benowitz NL., FitzGerald GA., Corbridge S., Heath J., Hahn E., et al., "Impact of Smokeless Tobacco Products on Cardiovascular Disease: Implications for Policy, Prevention, and Treatment: A Policy Statement From the American Heart Association", Circulation [Internet], Ovid Technologies (Wolters Kluwer Health), vol/issue: 122(15), pp. 1520-44, 2010. Available from: http://dx.doi.org/10.1161/cir.0b013e3181f432c3.

[2] American Diabetes Association, "Cardiovascular disease and risk management", Diabetes Care, vol. 38, pp. S49S57, 2015. Available from: http://dx.doi.org/doi: 10.2337/dc15-S011.

[3] Centers for Disease Control and Prevention, "Economic facts about U.S. tobacco production and use", 2015. Available from: http://www.cdc.gov/tobacco/data_statistics/fact_sheets/economics/ econ_facts/.

[4] Centers for Disease Control and Prevention, "High blood pressure fact sheet", 2015. Available from: http://www.cdc.gov/dhdsp/data_statistics/fact_sheets/fs_bloodpressure.htm. Accessed November 152015.

[5] American Heart Association, "Tobacco and blood pressure", 2015. Available from: http://www.heart.org/HEARTORG/Conditions/HighBloodPressure/PreventionTreatmentofHighBloodPressure/Tob acco-and-Blood-Pressure_UCM_301886_Article.jsp\#.

[6] Gupta R., Gurm H., Bartholomew JR., "Smokeless Tobacco and Cardiovascular Risk", Archives of Internal Medicine [Internet], American Medical Association (AMA), vol/issue: 164(17), pp. 1845, 2004. Available from: http://dx.doi.org/10.1001/archinte.164.17.1845.

[7] O'Connor RJ., "Non-cigarette tobacco products: what have we learnt and where are we headed? Tobacco Control" [Internet]. BMJ, vol/issue: 21(2), pp. 181-90, 2012. Available from: http://dx.doi.org/10.1136/tobaccocontrol-2011050281.

[8] University of North Carolina, "Non-cigarette tobacco products and POS policies", 2014. Available from: http://countertobacco.org/non-cigarette-tobacco-products-and-pos-policies.

[9] Asplund K., "Smokeless tobacco and cardiovascular disease", Progress in cardiovascular diseases [Internet]. Elsevier BV, vol/issue: 45(5), pp. 383-94, 2003. Available from: http://dx.doi.org/10.1053/pcad.2003.00102.

[10] Benowitz NL., "Sodium Intake from Smokeless Tobacco", $N$ Engl J Med [Internet]. New England Journal of Medicine (NEJM/MMS), vol/issue: 319(13), pp. 873-4, 1988. Available from: http://dx.doi.org/10.1056/nejm198809293191318.

[11] Valeriano J., Tucker P., Kattah J., "An unusual cause Ofhypokalemic muscle weakness", Neurology [Internet]. Ovid Technologies (Wolters Kluwer Health), vol/issue: 33(9), pp. 1242-1242, 1983. Available from: http://dx.doi.org/10.1212/wnl.33.9.1242.

[12] Eliasson M., Asplund K., Nasic S., Rodu B., "Influence of smoking and snus on the prevalence and incidence of type 2 diabetes amongst men: the northern Sweden MONICA study", Journal of Internal Medicine [Internet], Wiley-Blackwell, vol/issue: 256(2), pp. 101-10, 2004. Available from: http://dx.doi.org/10.1111/j.13652796.2004.01344.

[13] Pankova A., Kralikova E., Fraser K., Lajka J., Svacina S., Matoulek M., "No difference in hypertension prevalence in smokers, former smokers and non-smokers after adjusting for body mass index and age: a cross-sectional study from the Czech Republic, 2010", Tobacco Induced Diseases [Internet], Springer Science + Business Media, vol/issue: 13(1), 2015. Available from: http://dx.doi.org/10.1186/s12971-015-0049-4.

[14] Siegel D., Benowitz N., Ernster VL., Grady DG., Hauck WW., "Smokeless tobacco, cardiovascular risk factors, and nicotine and cotinine levels in professional baseball players", American Journal of Public Health [Internet], American Public Health Association, vol/issue: 82(3), pp. 417-21, 1992. Available from: http://dx.doi.org/10.2105/ajph.82.3.417.

[15] Benowitz NL., "Daily Use of Smokeless Tobacco: Systemic Effects", Ann Intern Med [Internet], American College of Physicians, vol/issue: 111(2), pp. 112, 1989. Available from: http://dx.doi.org/10.7326/0003-4819-111-2-112.

[16] Fernandez De Bobadilla J., Garrido P., López De Sá E., Sanz-De-Burgoa V., "Cardiovascular risk factors in smokers vs non-smokers in a primary care setting: retratos study: PP.20.305", Journal of Hypertension [Internet], Ovid Technologies (Wolters Kluwer Health), vol. 28, pp. 1, 2010. Available from: http://dx.doi.org/10.1097/01.hjh.0000379231.39482.f8. 
[17] Hergens MP., Lambe M., Pershagen G., Ye W., "Risk of hypertension amongst Swedish male snuff users: a prospective study", Journal of Internal Medicine [Internet], Wiley-Blackwell, vol/issue: 264(2), pp. 187-94, 2008. Available from: http://dx.doi.org/10.1111/j.1365-2796.2008.01939.x

[18] Bullock L. AHA., "Smokeless Tobacco Products Are Unsafe", Internal Medicine News [Internet], Elsevier BV, vol/issue: 43(16), pp. 30, 2010. Available from: http://dx.doi.org/10.1016/s1097-8690(10)70838-6.

[19] England LJ., Kim SY., Tomar SL., Ray CS., Gupta PC., Eissenberg T., et al., "Non-cigarette tobacco use among women and adverse pregnancy outcomes", Acta Obstet Gynecol Scand [Internet], Wiley-Blackwell, vol/issue: 89(4), pp. 454-64, 2010. Available from: http://dx.doi.org/10.3109/00016341003605719.

[20] Weber MA., Schiffrin EL., White WB., Mann S., Lindholm LH., Kenerson JG., et al., "Clinical Practice Guidelines for the Management of Hypertension in the Community A Statement by the American Society of Hypertension and the International Society of Hypertension", Journal of Hypertension [Internet], Ovid Technologies (Wolters Kluwer Health), vol/issue: 32(1), pp. 3-15, 2014. Available from: http://dx.doi.org/10.1097/hjh.0000000000000065.

[21] Deaton A., "Panel data from time series of cross-sections", Journal of Econometrics [Internet], Elsevier BV, vol/issue: 30(1-2), pp. 109-26, 1985. Available from: http://dx.doi.org/10.1016/0304-4076(85)90134-4.

[22] Molenberghs, G., Verbeke, G., "Models for discrete longitudinal data", Springer, New York, 2005.

[23] Liu Q., Pierce DA., "A note on Gauss-Hermite quadrature", Biometrika [Internet], Oxford University Press (OUP), vol/issue: 81(3), pp. 624-9, 1994. Available from: http://dx.doi.org/10.1093/biomet/81.3.624.

[24] Friedman GD., Klatsky AL., Siegelaub AB., "Alcohol, tobacco, and hypertension", Hypertension [Internet], Ovid Technologies (Wolters Kluwer Health), vol/issue: 4(5_Pt_2), pp. III143-III143, 1982. Available from: http://dx.doi.org/10.1161/01.hyp.4.5_pt_2.iii143.

\section{BIOGRAPHIES OF AUTHORS}
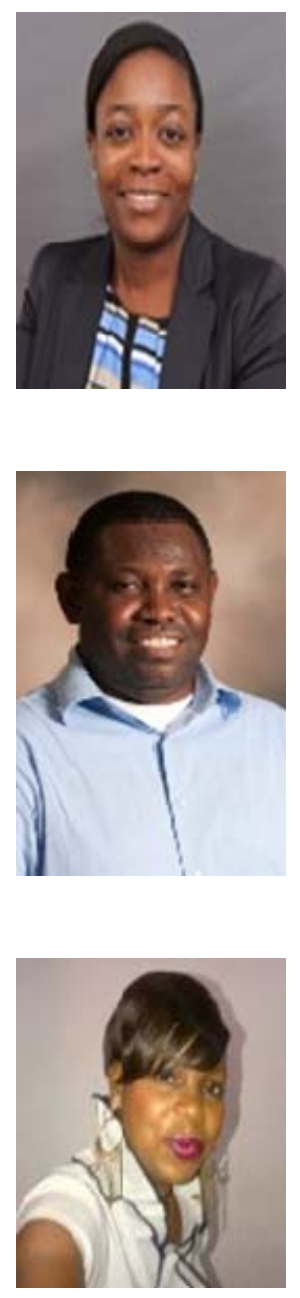

Olawunmi Obisesan is an adjunct faculty in the Department of Social Work at Southeast Missouri State University, Missouri, USA. Olawunmi holds several degrees including a $\mathrm{PhD}$ in Public Health (Epidemiology) from Walden University. She is currently completing another doctoral program in Health Education from A.T. Still University and an MPH program in Prevention Science from Emory University, Rollins School of Public Health. Olawunmi has worked with several hospitals, and is currently the Coordinator for the Regional Arthritis Center (RAC) for 16 counties in Southeast Missouri. Under the RAC program, Olawunmi has implemented several CDC-funded evidence-based programs for the State of Missouri, including the Stanford University's Chronic Disease Self-Management Program (CDSMP). Olawunmi's research interests include issues that affect the health of vulnerable populations, especially immigrants.

Emmanuel Thompson is an Assistant Professor of Statistics/Actuarial Science in the Department of Mathematics at Southeast Missouri State University, Missouri, USA. He is a Graduate Statistician member of the American Statistical Association and also an Affiliate member of the Institute and Faculty of Actuaries in the United Kingdom. Emmanuel holds a Ph.D. in Statistics (Actuarial Science option) and a MSc. in Actuarial Science both from University of Calgary in Canada. He also graduated from University of Cape Coast in Ghana, with a BSc. (First Class) in Statistics and has spent over six years working in the insurance industry in Ghana and briefly in Canada. Emmanuel's research agenda covers the areas of risk theory \& actuarial modeling, applied statistics, and applied econometrics. Emmanuel has published and presented different peer reviewed papers in Applied Statistics and Actuarial Science at the national and international levels

OlubusayoAkinola is a drug demand reduction expert for the European Union Support Project to Economic Community of West African States (ECOWAS) Regional Action Plan on illicit drug trafficking, related organized crime and drug abuse in West Africa. She is a pharmacist, who also has a PhD in Public Health with specialization in Epidemiology. Her level of work-based experience in the region increased her passion for examining harm minimization among drugusing populations through effective public health interventions. 


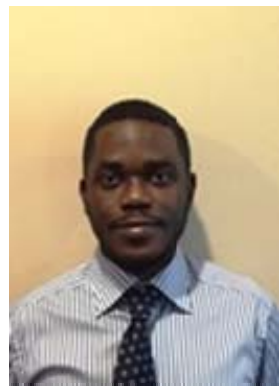

Adekunle Obisesan is an Adult Internal Medicine/Critical Care Hospitalist physician at Southeast Hospital, Cape Girardeau, Missouri. Adekunle also holds a MPH degree from Johns Hopkins Bloomberg School of Public Health.Adekunle's work experiences include workingas the Integrated Management of Childhood Illnesses and Immunizations Program Officer with the United States Agency for International Development's Basic Support for Institutionalizing Child Survival (BASICS) project. He has extensive experience developing, implementing and evaluating interventions and treatment protocols for the prevention and management of various childhood diseases at the primary care level. Adekunle is also anAdjunct Clinical Preceptor (Medical students' education) at A.T. Still University Kirksville College of Osteopathic Medicine.

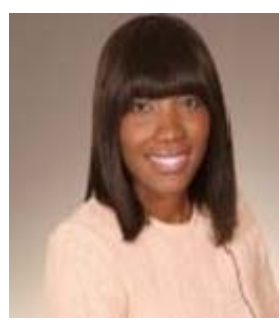

Yvonne Commodore-Mensah is an Assistant Research Professor in the Department of Nursing at Emory University, Nell Hodgson Woodruff School of Nursing. Yvonne holds a Ph.D. in Nursing from Johns Hopkins University and BSN(Honors) from Fairleigh Dickinson University. Yvonne's research interest is primarily cardiovascular risk reduction in ethnic minority populations-particularly those of African descent. 